\title{
Neurofibromatosis Type 1 or Von Recklinghausen Disease: About Three Cases to the National Hospital of Niamey and Literature Review
}

\author{
M. Daou ${ }^{*}$, H. Sidibé2, A. Andia 3 , M. J. Y. Araoye1, M. Konaté3, Z. Mamadou², Y. Abba Kaka ${ }^{4}$, \\ D. I. Bako5, S. Beydou1, S. Brah ${ }^{3}$, L. Salissou' ${ }^{1}$, E. Adehossi' ${ }^{3}$, S. Sanoussi ${ }^{4}$ \\ ${ }^{1}$ Department of Internal Medicine, Hôpital National de Niamey, Niamey, Niger \\ ${ }^{2}$ Department of Neurology, Hôpital National de Niamey, Niamey, Niger \\ ${ }^{3}$ Department of Internal Medicine, Hôpital General de Reference, Niamey, Niger \\ ${ }^{4}$ Department of Surgery, Hôpital National de Niamey, Niamey, Niger \\ ${ }^{5}$ Department of Radiology, Hôpital General de Reference, Niamey, Niger \\ Email: *daoumo@yahoo.fr
}

How to cite this paper: Daou, M., Sidibé, H., Andia, A., Araoye, M.J.Y., Konaté, M., Mamadou, Z., Kaka, Y.A., Bako, D.I., Beydou, S., Brah, S., Salissou, L., Adehossi, E. and Sanoussi, S. (2021) Neurofibromatosis Type 1 or Von Recklinghausen Disease: About Three Cases to the National Hospital of Niamey and Literature Review. Open Journal of Internal Medicine, 11, 175-187. https://doi.org/10.4236/ojim.2021.113013

Received: August 12, 2021

Accepted: September 15, 2021

Published: September 18, 2021

Copyright $\odot 2021$ by author(s) and Scientific Research Publishing Inc. This work is licensed under the Creative Commons Attribution International License (CC BY 4.0).

http://creativecommons.org/licenses/by/4.0/

\begin{abstract}
We report three cases of neurofibromatosis type 1 disease with literature review, collected in the department of neurology and internal medicine from National Hospital of Niamey (HNN). Two of them were men and the first signs were noted by the mother at the birth in 2 cases. Only one case of consanguinity was observed. Clinically, light brown spots on the skin, neurofibromas, Lisch nodules were constantly observed. Histopathological's exam confirmed neurofibromas. Moreover, cutaneous and ophthalmological manifestations lead to the diagnostic. Two cases of orthopedic complications were observed: one scoliosis and one Congenital dysplasia of the long bones. There was no specific treatment. Neurofibromatosis type 1 or von Recklinghausen's disease is the most frequent phacomatosis and its diagnosis is usually composed of a set of clinical criteria of the National Institute Health (Bethesda, 1988).
\end{abstract}

\section{Keywords}

Von Recklinghausen Disease, NIH Criteria, Niger

\section{Introduction}

Phacomatoses also known as neurocutaneous syndromes, represent a diverse group of congenital disorders that encompass abnormalities of neuroectodermal 
and, at times, mesodermal development, hence preferentially manifesting as malformations in the skin, eye, and central nervous system (CNS) [1].

These are hereditary or congenital diseases having variable modes of transmission [1]:

- Neurofibromatosis type 1 (NF1) and type 2 (NF2).

- Tuberous sclerosis of Bourneville.

- Von Hippel-Lindau disease.

- Sturge-Weber-Krabbe syndrome.

- And various neuro-ectodermal dyssembryoplasias.

Neurofibromatosis type 1 (NF1) or Von Recklinghausen disease is one of the most frequent autosomal dominant genetic disorders [2].

NF1 is subject to great phenotypic variability. The diagnostic is based on the National Institute of Health in Bethesda criteria (1988) constituted in the simultaneous presence of light brown spots on the skin, neurofibromas, and Lisch nodules [3].

NF1 patients have a cumulative lifetime risk of developing malignant peripheral nerve sheath tumors (MPNST) of $8 \%-16 \%$ and occurs mostly at ages $20-35$ years [4]-[9]. Most, if not all, MPNSTs in patients with NF1 appear to develop from preexisting plexiform neurofibromas or non-dermal neurofibromas which have undergone malignant transformation [6] [10] [11]. Seventy percent of these tumors are of high-grade that can metastasize widely and entail a poor prognosis [7].

Congenital dysplasia of the long bones (mostly tibia but also fibula, radius and ulna) is a classic manifestation of NF1 (7.2\%) [11]. Bowing of long bones leads to visible deformity and fragile bone that is susceptible to fracture [12]. Repeated fractures with failure to heal can lead to the development of pseudarthrosis (failure of primary union of the separate bone ends can create a false joint) $(2 \%-3.6 \%)$ [11] [13].

The great clinical variability of this disease, its tumor risks and its totally unpredictable evolution impose an early management with a regular follow-up of the affected subjects.

The treatment of NF1 is essentially symptomatic. However, significant advances in research allow us to reasonably open therapeutic perspectives in the medium and long term [3].

NF1 remains an underestimated disease and is not well known by the population. Indeed, apart from the aesthetic damage, patients very rarely consult a doctor.

We report three cases of neurofibromatosis type 1 disease with literature review, collected in the department of neurology and internal medicine from $\mathrm{Na}$ tional Hospital of Niamey

\section{Observations}

\section{Observation 1}

1) M., consults for subcutaneous nodules. 
The diagnosis of Von Recklinghausen's disease was retained on the association of cutaneous signs (presence of more than six light brown spots on the skin larger than $5 \mathrm{~mm}$ with neurofibromas: Figure 1, Figure 2), ophthalmological signs (bilateral Lisch nodules).

The patient was under surveillance and did not receive any specific treatment. Currently, she is pubescent and only complains of an increase in the size of the subcutaneous neurofibromas which are beginning to be aesthetically embarrassing.

In the future, surgical removal of the subcutaneous neurofibromas may be considered.

Regular follow-up is maintained because of the risk of malignant degeneration:

Clinically: sensitivity, size, consistency.

Paraclinical: skin biopsy, extension assessment: CT scan or MRI.

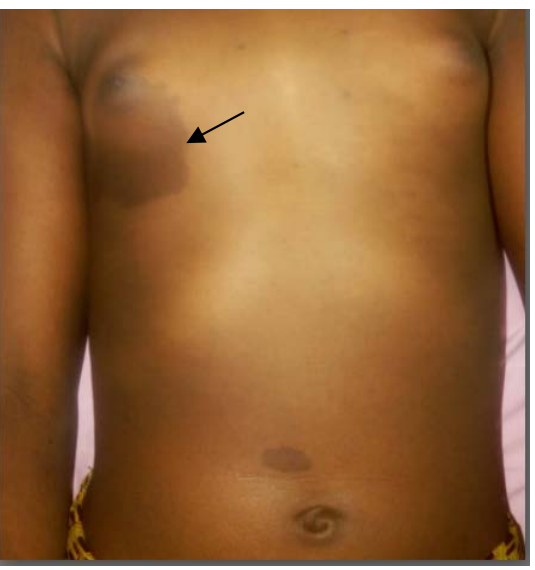

(a)

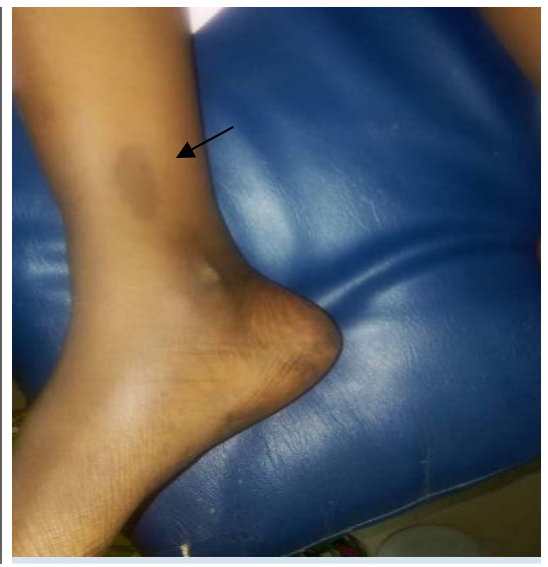

(b)

Figure 1. (a) Light brown spots on the skin observed in case 1; (b) Hyperchromiques Macules observed in case 1.

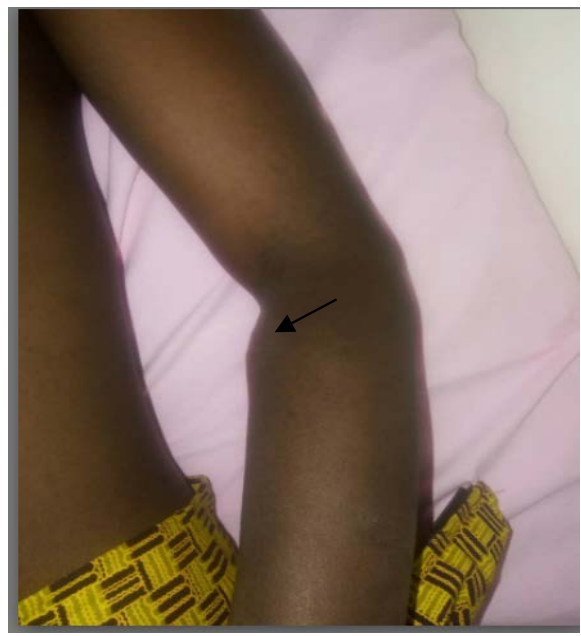

Figure 2. Subcutaneous neurofibromas $\mathrm{Ob}$ served in case 1 . 


\section{Observation 2}

E. M., consults for cutaneous nodules.

The diagnosis of Von Recklinghausen's disease was retained on the association of cutaneous signs (cutaneous neurofibromas disseminated all over the body: Figure 3), ophthalmological signs (bilateral Lisch nodules: Figure 4) and orthopedic signs (scoliosis-like deformation of the spine).

The patient was put under surveillance without any specific treatment.

An Orthopedic consult was requested regarding his scoliosis (Figure 5).

At present, any complaints but aesthetic discomfort that prevents him from having a normal social life for a man of his age. A psychological consultation was instituted.

Surgical removal of the largest and most unsightly cutaneous neurofibromas may be considered.

Regular follow-up is maintained because of the risk of malignant degeneration:

Clinically: tenderness, size, consistency.

Paraclinical: skin biopsy, extension assessment (CT scan or MRI).

\section{- Observation 3}

I.H., consults for right leg pain.

The diagnosis of Von Recklinghausen's disease was retained on the association of subcutaneous signs (subcutaneous neurofibromas disseminated all over the body), ophthalmological signs (bilateral Lisch nodules: Figure 6) and orthopedic signs (Congenital dysplasia of the long bones (tibia and fibula, ulna).

The patient was put under surveillance without any specific treatment.

An Orthopedic consult was requested regarding his Congenital dysplasia of the long bones.

At present, any complaints but aesthetic discomfort that prevents him from having a normal social life for a man of his age. A psychological consultation was instituted.

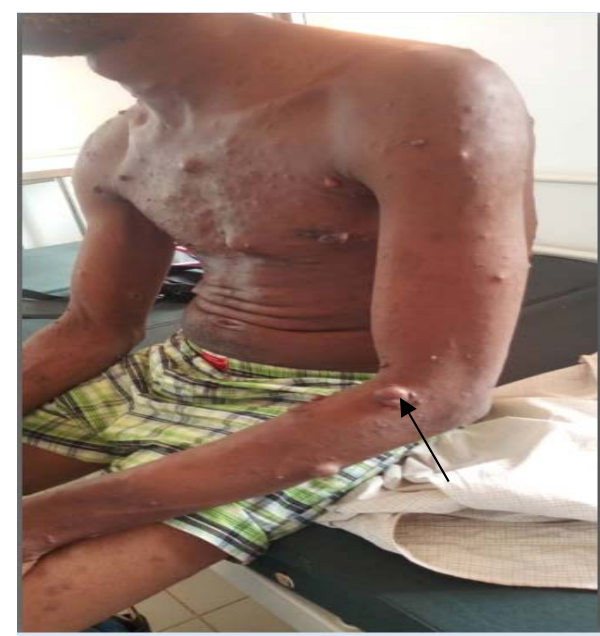

(a)

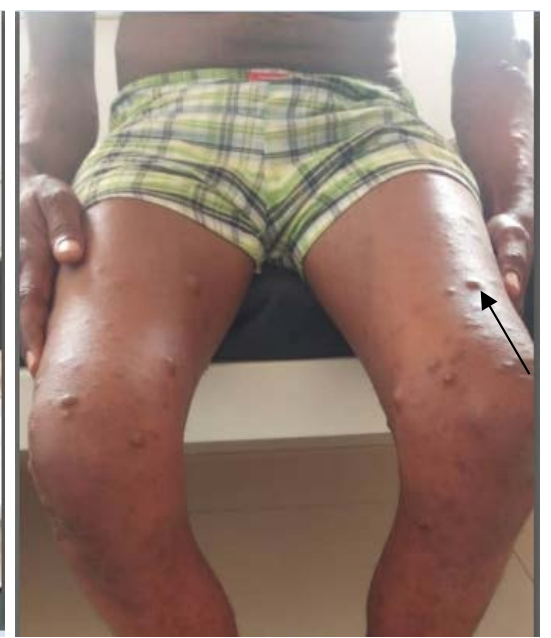

(b)

Figure 3. Cutaneous neurofibromas observed in case 2. 


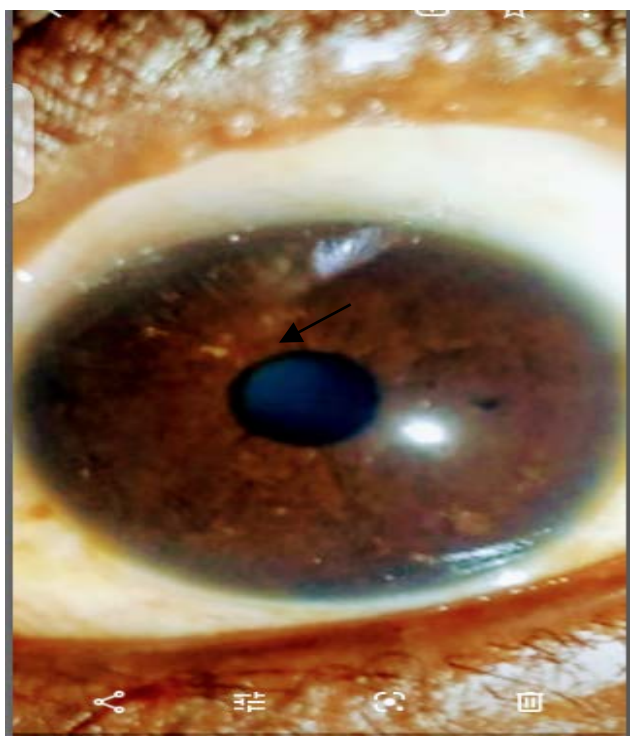

Figure 4. Lisch nodules observed in case 1.

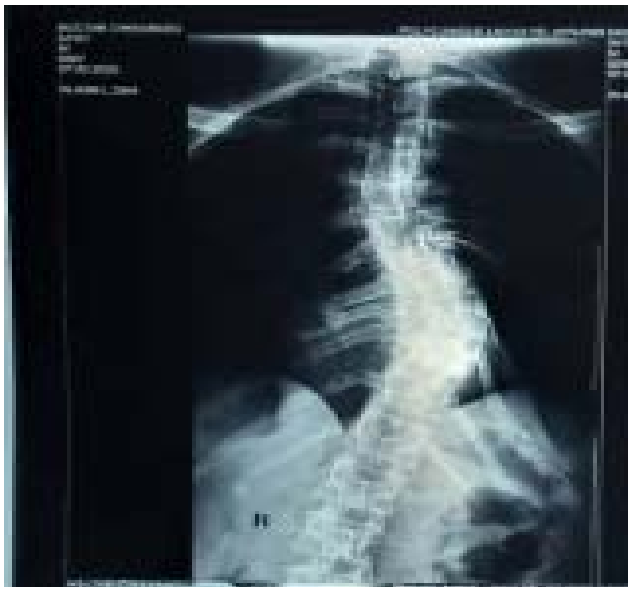

Figure 5. Rachis radiograph image of case 2 showing scoliosis.

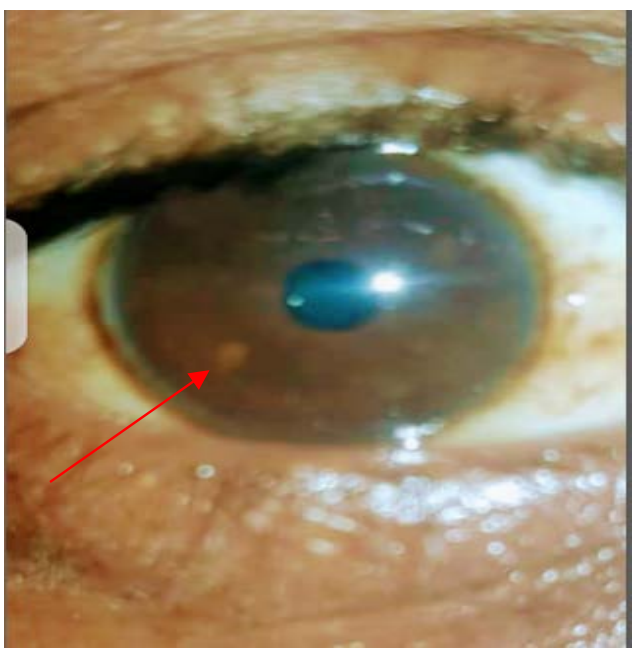

Figure 6. Lisch Nodules observed in case 3. 
Surgical removal of the largest and most unsightly cutaneous neurofibromas may be considered.

Regular follow-up is maintained because of the risk of malignant degeneration:

Clinically: tenderness, size, consistency.

Paraclinical: skin biopsy, extension assessment: CT scan or MRI.

\section{Discussion}

Neurofibromatosis type 1 (NF1) is the most frequent of the phacomatoses and neurofibromatosis. It accounts for $95 \%$ of all NFs, with a prevalence of approximately one in 4000 individuals, and an incidence of approximately one in 3000 to 3500 births, with a homogeneous worldwide distribution [3]. Patients with NF1 are estimated to number 2 to 3 million worldwide.

In France, the number of NF1 patients is estimated at 20,000, whereas in America, the figure is higher and close to 100,000 [14]. In Africa: 11 cases of NF1, over a period of 10 years, were found in 2006 in Guinea [8], while in Bamako, 16 cases of neurofibromatosis type 1 over 5 years, were recorded in 2010 [9]. 124 patients with Neurofibromatosis 1 were seen during two studies at Ilori and Benin City, Nigeria [15] [16]. In Niger, there is not yet a register of NF1 patients.

There is no predominance of sex (sex ratio $=1)$ or race, women and men are affected in the same way [7] [17].

In our series the 3 cases are divided into one female and two males (Table 1). Cissé A, and coll in Bamako, Odebode T.O and coll in Ilori found a sex ratio F/H $=1.5$ [15] [16]. The first clinical manifestations are rare before the age of 5 years. However, the clinical signs may be present from birth or only appear in adulthood. Its penetrance is almost complete at the age of 8 years [3].

In our series, our 3 patients are relatively young, aged respectively 14, 18 and 30 years. This can be explained by the appearance of neurofibromas most often from puberty onwards [10] [11], which is the reason for consultation.

Neurofibromatosis type 1 (NF1) or Von Recklinghausen disease is a genetic disorder with autosomal dominant transmission [12], with an incidence of 1 in 3500 births of which $50 \%$ of the cases are sporadic, covering de novo mutations, a patient can transmit the disease to each of his or her children with a risk of $50 \%$ whatever the sex. Between $30 \%$ and $50 \%$ of patients have neomutations and in this case, neither of the patient's parents is ill [13]. The great phenotypic variability of this disease may lead to the presence of a family history being overlooked. Approxymately $50 \%$ of cases have a family history of autosomal dominant transmission [15] [16].

Its search is therefore done through a rigorous interrogation [13].

In our series, none of the patients had a relative with NF1 (Table 1).

Consanguineous marriages are sometimes the source of rare and mostly severe genetic disease [14]. The reason for this statement is unknown. In Great 
Table 1. Socio-demodraphic and clinical presentation of neurofibromas type 1 .

\begin{tabular}{|c|c|c|c|}
\hline & No. 1 & No. 2 & No. 3 \\
\hline Sex & Female & male & Male \\
\hline Age & 14 years & 30 years & 18 years \\
\hline Marital status & Not married & married & Not married \\
\hline Profession & student & trader & student \\
\hline medical background & No & hypertension & No \\
\hline Consanguinity & No & first degree & No \\
\hline Date of onset & 05/07/2017 & 15 years & 18 years \\
\hline Tâches café au lait macules & 18 & No & 09 \\
\hline Subcutaneous nodules & 10 & No & 04 \\
\hline Cutaneous nodule & No & 50 skin nodules & No \\
\hline Lisch nodules & Yes & Bilateral & Yes \\
\hline Neurofibromas & Yes & yes & Yes \\
\hline CNS injuries & No & No & No \\
\hline Histopathologic exam & Yes & yes & Yes \\
\hline Other complications & No & scoliosis of the spine & $\begin{array}{l}\text { Congenital dysplasia of the long } \\
\text { bones (tibia and fibula, ulna }\end{array}$ \\
\hline Duration of follow-up & 4 years & 14 months & 8 months \\
\hline $\begin{array}{l}\text { complications } \\
\text { after treatment }\end{array}$ & No & No & No \\
\hline
\end{tabular}

Britain, about $35 \%$ of children with rare genetic diseases are the result of a consanguineous marriage [14]. In our series, case number 2 is from a consanguineous marriage.

In our series, café au lait spots were present in patient number 1 and 3 , and absent in patient number 2 (Table 1). This may be due to the fact that café au lait spots are the first signs of the disease [3]. In adolescence, they are present in more than $99 \%$ of cases, in adult life they often become paler, inconspicuous and some disappear [15]. Neurofibromas were present in all 3 patients. This can be explained by the fact that patients consult most often after the appearance of neurofibromas or when they become troublesome.

Cissé A, et al. in Bamako found that café au lait spots and neurofibromas were present in all their patients. All patients had neurofibromas, with Odebode T.O and coll study in Ilori [15] [16]. The age of onset of café au lait spots existed from birth. These results have been demonstrated in the literature, which states that the age of onset of café -au-lait spots is most often congenital or within the first 2 years of life [3].

The café au lait spots were dark brown in color. This is consistent with some studies in the literature [5] [15] [16]. The diameters of the café au lait spots ranged from $5 \mathrm{~mm}$ to $12 \mathrm{~cm}$. Some studies [5] [15] [16], say that the diameter of the café au lait stains varies from 0.5 to $50 \mathrm{~cm}$ but the majority of them are less 
than $10 \mathrm{~cm}$. The café au lait spots were scattered all over the body without any preferential location [17] [18].

This is consistent with the literature. Indeed, for some authors [3], the distribution of café au lait spots is random. No study has yet given a predilection place for the café au lait macules.

In our series, patient number 1 and 3 underwent the counting of the number of café au lait spots, and they were respectively 18 and 9. For Cissé A, et al in Bamako, patients with a number of café au lait spots between 11 and 20 were in the majority at $45.4 \%$. No study has determined a fixed number of café au lait spots in a patient. The patient had café au lait spots with well-defined contours as in other studies in the literature [5] [15] [16].

The age of onset of neurofibromas was 11, 15 and 16 years for patients number 1, 2 and 3 respectively. Other works have found similar results, which say that neurofibromas rarely appear in early childhood [16]. For some, they appear only at puberty and are present in 95\% of NF1 patients in adulthood [19] [20].

In our series we recorded 2 types of neurofibromas: cutaneous and subcutaneous, this is in line with the literature which states that depending on where the tumor develops on the peripheral nerve pathway: from the small intradermal nerve endings to the large nerve trunks, the tumor developed will be, cutaneous, subcutaneous or plexiform [21] [22]. The size and number of neurofibromas was variable in our series as in the literature [16].

In our series, cutaneous neurofibromas are on all parts of the body for the patient. Like ours, other studies [16] [22], say that the main site of neurofibromas is the trunk, but other parts of the body are not spared.

Lisch nodules, were found in our 3 patients aged 14 and 30 years respectively, which is consistent with some studies that state that Lisch nodules are rare before six years, they are present in more than $90 \%$ of cases after 16 years [7] [15] [23]. Other manifestations such as optic tract glioma [24], lentigines, neurological, endocrine... were not detected.

On the other hand, patient number 2 presented an orthopedic complication such as scoliosis, which is in line with the literature: Scoliosis is the most frequent bone manifestation, it evolves from a very young age without any relation to a growth spurt. It is found in $10 \%$ to $30 \%$ of NF1 cases [16].

Aesthetic damage was present in our patients. The priority request of the patients in our study was the treatment of neurofibromas which were unsightly. According to one study [12], the aesthetic impact can sometimes be considerable, resulting in social handicap. Cutaneous neurofibromas often have serious psychological and social consequences because of their displaying, sometimes spectacular character [7]. The ophthalmological assessment was requested in our study, with the aim of detecting Lisch nodules or iris hamartomas, the presence of which is pathognomonic of neurofibromatosis type 1 [7]. Lisch nodules were found in our 3 patients.

The brain scan was requested in 2 of our patients to look for an optic tract glioma which is the most frequent intracerebral tumor in NF1 [16], and which is 
most often asymptomatic [19]. Cerebral CT scan is also systematically proposed by some authors such as Riccardi [25]. For others, neuroimaging is only essential if there are neurological and/or ophthalmological signs suggestive of a cerebral anomaly [20]. The brain scan was normal in our 2 patients.

Indeed, the average age of onset of optic tract glioma is 4 to 5 years [16].

Bone radiography was requested in all 3 patients. Patient number 2 had a scoliosis-like deformity of the spine.

Some authors believe that bone radiographs should be part of the initial workup of NF1 because the study of the spine (clinical and radiological) is of diagnostic interest since it is one of the privileged sites of the disease [17] [25] [26].

Biopsy and anatomopathological examination helped us in the histopathological diagnosis of neurofibromas.

Histologically, neurofibromas are heterogeneous tumors. They are formed by the proliferation of Schwann cells, neurons, perineural cells, fibroblasts and mast cells [21].

This is consistent with the findings in our patients. Abdominal ultrasound was performed in our patients to look for deep neurofibromas.

For some authors, its systematic practice in the initial workup of NF1 is controversial. However, it may be useful in the search for deep neurofibromas [17]. Depending on the series, involvement of the gastrointestinal tract is present in $12 \%$ to $40 \%$ of NF1 cases, mainly after 11 years of age. The frequency of digestive neurofibromas has been estimated to be about $2 \%$ of patients [17] [21].

Cardiac ultrasound was normal in our 3 patients. In the literature, it is said that it is not systematically performed in the initial work-up of NF1. However, cases of cardiac tumors have been described in adults and children with Von Recklinghausen disease [18], as well as other cardiac pathologies [17] [27] [28] [29] [30].

In our study, cutaneous and ophthalmological manifestations were sufficient to make the diagnosis.

Treatment for neurofibromatosis type 1 depends on the symptoms that a patient has (dermal neurofibromas, bony lesions, malignant peripheral nerve sheath tumors, brain tumors).

To date, there is no specific treatment for neurofibromatosis type 1. The management of NF1 patients therefore consists of regular, essentially clinical, surveillance and treatment of complications when they appear [17].

It is essentially, if not exclusively, surgery, which is the preferred treatment, since there is no other therapeutic initiative, neither preventive nor curative of the disease [31]. This surgery is only palliative, as it does not modify the general evolution of the disease. However, significant advances in research allow us to reasonably open up therapeutic perspectives in the medium term [3].

In the literature, the case of a first observation of an adult with NF1 complicated with inoperable deep spinal plexiform neurofibromas treated successfully with trametinib, an anti-MEK has been reported. Von Recklinghausen disease 
exposes patients to social disability. Neurofibromas were the major complaint in our 3 patients because of their unaesthetic character. The only possible treatment remains surgical [31] [32] [33].

In our series, no patient benefited from surgical treatment. Patient number 2 is undergoing psychotherapy and orthopedic follow-up. The need for psychological support for patients and their families should be evaluated systematically and offer it when needed. Social support should be offered to patients and their families, along with guidance and advise through the various domains of social intervention [17] [24].

\section{Conclusions}

Neurofibromatosis type 1 or Von Recklinghausen disease is one of the most frequent genetic diseases. It is part of the phacomatoses. Its penetrance is almost complete at the age of 8 years.

NF1 is characterized by a very high variability of its clinical expression, even within the same family. Its diagnosis is based on international clinical criteria defined in 1988. The clinical polymorphism of this disease, its tumor risks and its totally unpredictable evolution which can put at stake the vital prognosis, impose an early management with a regular follow-up of the affected subjects.

Unfortunately, the therapeutic strategy is still limited to the treatment of the different manifestations. However, with gene therapy, it will be possible in the near future to intervene at the very origin of the disturbances and to palliate all the pathological consequences.

The development of multidisciplinary centers for the care of NF1 patients will improve the level of knowledge of professionals and the population, homogenize monitoring and treatment procedures, and establish phenotype-genotype correlations facilitating prevention, monitoring and support of patients.

In our series, the epidemiological, clinical, paraclinical and therapeutic data are the same with the literature.

This disease is probably underestimated in our region due to the absence of previous regular studies on NF1.

\section{Conflicts of Interest}

The authors declare no conflicts of interest regarding the publication of this paper.

\section{References}

[1] De Ribaupierre, S., Vernet, O., Vinchon, M. and Rilliet, B. (2008) Phacomatoses et tumeurs génétiquement determinées: La transition enfant-adulte. Neurochirurgie, 54, 642-653. https://doi.org/10.1016/j.neuchi.2008.07.004

[2] Dietemann, J.L. and Koob, M. (2014) Imagerie de la neurofibromatose type 1. EMCRadiologie et Imagerie Médicale Musculosqueletique, Neurologique, Maxillofaciale, 1-13.

[3] Vidaud, D., Levy, P., Laurendeau, I., Parfait, B., Bieche, I. and Vidaud, M. (2008) 
Approche moléculaire des MPNSTs dans la neurofibromatose de type 1: Vers l'identification de marqueurs diagnostiques et pronostiques. Archives de Pédiatrie, 15, 809-811. https://doi.org/10.1016/S0929-693X(08)71921-3

[4] Uusitalo, E., Rantanen, M., Kallionpää, R.A., Pöyhönen, M., Leppävirta, J., Ylä-Outinen, H., Riccardi, V.M., Pukkala, E., Pitkäniem, J., Peltonen, S., et al. (2016) Distinctive Cancer Associations in Patients with Neurofibromatosis Type 1. Journal of Clinical Oncology, 34, 1978-1986. https://doi.org/10.1200/JCO.2015.65.3576

[5] Evans, D.G., Baser, M.E., McGaughran, J., Sharif, S., Howard, E. and Moran, A. (2002) Malignant Peripheral Nerve Sheath Tumours in Neurofibromatosis 1. Journal of Medical Genetics, 39, 311-314. https://doi.org/10.1136/jmg.39.5.311

[6] Khosrotehrani, K., Bastuji-Garin, S., Riccardi, V.M., Birch, P., Friedman, J.M. and Wolkenstein, P. (2005) Subcutaneous Neurofibromas Are Associated with Mortality in Neurofibromatosis 1: A Cohort Study of 703 Patients. American Journal of Medical Genetics Part A, 132A, 49-53. https://doi.org/10.1002/ajmg.a.30394

[7] Ferner, R.E. and Gutmann, D.H. (2002) International Consensus Statement on Malignant Peripheral Nerve Sheath Tumors in Neurofibromatosis. Cancer Research, 62, 1573-1577.

[8] Ducatman, B.S., Scheithauer, B.W., Piepgras, D.G., Reiman, H.M. and Ilstrup, D.M. (1986) Malignant Peripheral Nerve Sheath Tumors. A Clinicopathologic Study of 120 Cases. Cancer, 57, 2006-2021.

https://doi.org/10.1002/1097-0142(19860515)57:10<2006::AID-CNCR2820571022> 3.0.CO;2-6

[9] Evans, D.G., Huson, S.M. and Birch, J.M. (2012) Malignant Peripheral Nerve Sheath Tumours in Inherited Disease. Clinical Sarcoma Research, 2, Article No. 17. https://doi.org/10.1186/2045-3329-2-17

[10] Tucker, T., Wolkenstein, P., Revuz, J., Zeller, J. and Friedman, J.M. (2005) Association between Benign and Malignant Peripheral Nerve Sheath Tumors in NF1. Neurology, 65, 205-211. https://doi.org/10.1212/01.wnl.0000168830.79997.13

[11] King, A.A., Debaun, M.R., Riccardi, V.M. and Gutmann, D.H. (2000) Malignant Peripheral Nerve Sheath Tumors in Neurofibromatosis 1. American Journal of Medical Genetics, 93, 388-392.

[12] Heerva, E., Koffert, A., Jokinen, E., Kuorilehto, T., Peltonen, S., Aro, H.T. and Peltonen, J. (2012) A Controlled Register-Based Study of 460 Neurofibromatosis $1 \mathrm{~Pa}$ tients: Increased Fracture Risk in Children and Adults over 41 Years of Age. Journal of Bone and Mineral Research, 27, 2333-2337. https://doi.org/10.1002/jbmr.1685

[13] Ferner, R.E. (2007) Neurofibromatosis 1. European Journal of Human Genetics, 15, 131-138. https://doi.org/10.1038/sj.ejhg. 5201676

[14] Pinson, S. and Wolkenstein, P. (2005) La neurofibromatose 1 (NF1) ou maladie de Von Recklinghausen. La Revue de Médecine Interne, 26, 196-215.

https://doi.org/10.1016/j.revmed.2004.06.011

[15] Odebode, B.S., Afolayan, E.A.O., Adigun, I.A. and Daramola, O.O.M. (2005) Clinicopathological Study of Neurofibromatosis Type 1: An Experience in Nigeria. International Journal of Dermatologyy, 44, 116-120. https://doi.org/10.1111/j.1365-4632.2005.02386.x

[16] Bergqvist, C., Servy, A., Valeyrie-Allanore, L., Ferkal, S., Combemale, P. and Wolkenstein, P. (2020) Neurofibromatosis, French National Guidelines Based on an Extensive Literature Review Since 1966. Orphanet Journal of Rare Diseases, 15, Article No. 37. https://doi.org/10.1186/s13023-020-1310-3

[17] Onunu, A.N. and Lawal, N.A. (2002) Neurofibromatosis 1: A Clinical Study in the 
Nigerian African. Annals of Biomedical Science, 1, 118-123. https://doi.org/10.4314/abs.v1i2.40631

[18] Hernández-Martín, A. and Duat-Rodríguez, A. (2016) An Update on Neurofibroma tosis Type 1: Not Just Café-au-Lait Spots, Freckling, and Neurofibromas. An Update. Part I. Dermatological Clinical Criteria Diagnostic of the Disease. Actas Dermo-Sifiliográficas, 107, 454-464. https://doi.org/10.1016/j.ad.2016.01.004

[19] Jadayel, D., Fain, P., Upadhyaya, M., Ponder, M.A., Huson, S.M., Carey, J., et al. (1990) Paternal Origin of New Mutations in von Recklinghausen Neurofibromatosis. Journal of Natural Medicines, 343, 558-559. https://doi.org/10.1038/343558a0

[20] Shen, M.H., Harper, P.S. and Upadhyaya, M. (1996) Molecular Genetics of Neurofibromatosis Type 1 (NF1). Journal of Medical Genetics, 33, 2-17.

https://doi.org/10.1136/jmg.33.1.2

[21] Ars, E., Serra, E., Garcia, J., Kruyer, H., Gaona, A., Lazaro, C., et al. (2000) Mutations Affecting mRNA Splicing Are the Most Common Molecular Defects in Patients with Neurofibromatosis Type 1. Human Molecular Genetics, 9, 237-247.

https://doi.org/10.1093/hmg/9.2.237

[22] Friedman, J.M. and Birch, P.H. (1997) Type 1 Neurofibromatosis: A Descriptive Analysis of the Disorder in 1728 Patients. American Journal of Medical Genetics, 70, 138-143.

https://doi.org/10.1002/(SICI)1096-8628(19970516)70:2<138::AID-AJMG7>3.0.CO; $\underline{2-\mathrm{U}}$

[23] Madhaw, G., Samanta, R., Kumari, S. Radhakrishnan, D.M., Shree, R. and Kumar, N. (2019) Lisch Nodules-Ophtalmologique Marker of Neurofibroma 1. QJM: An International Journal of Medicine, 112, 934-935.

https://doi.org/10.1093/qjmed/hcz098

[24] Mammad, C., Mekaoui, N., Ouadghiri, F., Mammad, K. and Dakhama, B. (2017) Neurofibromatosis Type 1 in Four Children Cases. Neuroscience and Medicine, 8, 33-40. https://doi.org/10.4236/nm.2017.83005

[25] Riccardi, V.M. (2000) Von Recklinghausen Neurofibromatosis. The New England Journal of Medicine, 305, 1617-1627. https://doi.org/10.1056/NEJM198112313052704

[26] Zoller, M.E., Rembeck, B. and Akesson, H.O. (1995) Life Expectancy, Mortality and Prognostic Factors in Neurofibromatosis Type 1. A Twelve-Year Follow-Up of an Epidemiological Study in Goteborg, Sweden. Acta Dermato-Venereologica, 75, 136140.

[27] Duong, T., Sbidian, E., Valeyrie-Allanore, L., Vialette, C., Ferkal, S., Hadj-Rabia, S., et al. (2011) Mortality Associated with Neurofibromatosis 1: A Cohort Study of 1895 Patients in 1980-2006 in France. Orphanet Journal of Rare Diseases, 6, 1750 1763. https://doi.org/10.1186/1750-1172-6-18

[28] Danglot, G. and Fauvet, D. (1995) Neurofibromatosis 1 (NF1) mRNAs Expressed in the Central Nervous System Are Differently Spliced in the 5' Part of the Gene. $\mathrm{Hu}$ man Molecular Genetics, 300, 256-258. https://doi.org/10.1093/hmg/4.5.915

[29] Hagel, C., Peiper, M., Kluwe, L., Gotthard, S. and Friedrich, R.E. (2007) Histopathology and Clinical Outcome of NF1-Associated vs. Sporadic Malignant Peripheral Nerve Sheath Tumors. Journal of Neuro-Oncology, 82, 187-192. https://doi.org/10.1007/s11060-006-9266-2

[30] Pasmant, E., Laurendeau, I., Sabbagh, A., Parfait, B., Vidaud, M., Vidaud, D., et al. (2010) ANRIL ou l'étrange histoire d'un grand ARN non codant. Médecine/Sciences, 26, 564-566. https://doi.org/10.1051/medsci/2010266-7564 
[31] Friedrich, R.E. and Mautner, V.F. (2007) Malignant Peripheral Nerve Sheath Tumors (MPNST) in NF1-Affected Children. Anticancer Research, 27, 1957-1960.

[32] Eyenga, V., Eloundou, J., Ngowe, N., Atangana, R. and Sosso, M. (2008) Neurinomes et neurofibromes spinaux diagnostic et resultats du traitement chirurgical a Yaoundé. African Journal of Neurological Sciences, 27, 95-100.

[33] Benbelkacem, H. (2017) Prise en charge chirurgicale des manifestations faciales de la neurofibromatose type 1 ou maladie de Von Recklinghaussen: Nouvelles perspectives. Thèse de doctorat en sciences médicales, Université de Rabbat, Rabbat. 